\title{
ARTICLES
}

\section{Women newspaper editors in NZ Short term love affair}

\begin{abstract}
New Zealand has had three woman prime ministers, and was the first country in the world to give women the vote, but there is still a gender gap in leadership in the traditionally staid daily newspapers industry. One-third of the country's daily newspapers have never had a female editor. The low ratio of woman editors is incongruous with the fact the majority of journalism students are female, and a large number of new hires are women. This study interviewed every woman who has held the position of daily newspaper editor, which totals only 15 . The good news is that currently there are more women in editorships than ever before, but this still represents only 29 percent of daily editors. Attitudinal interviews show the editors love the job, but quit after only a few short years. However, this may be changing.
\end{abstract}

Keywords: daily newspapers, digital journalism, female newspaper editors, gender, journalism, New Zealand, professional collegiality, women leadership, collegial wilderness

\section{CATHERINE STRONG \\ Massey University, Wellington}

\section{Introduction}

-HIRTY years ago while working within the newsrooms I heard managers complain there were too many women in the newsrooms and that the industry was becoming feminised. This was an anecdotal observation, but when the first robust empirical research on gender equality in newsrooms was published it showed the opposite - that men dominated newsrooms. It showed women held lower-level jobs, were paid less than their male colleagues, and the middle and top levels were devoid of gender balance (Gray, 1984).

Similar studies throughout the years conclude that the gender imbalance remains in New Zealand newsrooms, and that is also mirrored in newsrooms throughout the Western world. This lack of women reporting the news is seen as a lack of diversity, and some argue it leads to fewer of women's voices and female-specific issues in the media (WMC, 2017; Byerly, 2011; Mills et al., 2017). 
This study focuses on the position of editor, the top person in daily newspapers who makes the ultimate decisions on which stories are published and how they are treated (Tai \& Chang, 2002). Daily newspaper industry is traditionally a top-down vertical management structure whereby unilateral decisions are often made by those in leadership positions (ibid.). Newspaper editors have been considered politically powerful and essential for democracy, since the editor acts as a weather vane in determining what is considered 'significant' to publish for the community. In the current media climate, daily newspapers are relevant to the population since their journalists regularly break unique news stories, even though the stories may be published online rather than in print (Amory, 2015; Aucoin, 2017; Wendland, 2002). Newspaper journalists produce news content for both newspapers and online which is common in New Zealand, where the two most significant online sites are owned by media companies that also produce the majority of daily newspapers, NZME and Fairfax Media (Myllylahti, 2017). As an example, Fairfax Media's online site (stuff.co.nz) has a reach of 3.5 million New Zealanders (ibid), which is considerable in a country with a total population of only 4.8 million (StatzNZ, Aug. 2017).

As discussed below, globally very few women work their way up to editor level, and New Zealand has the same gender imbalance as others, despite the country's strong history of gender equality. It was the first country in the world to give women the vote in 1893, and has had three prime ministers who are women, as well as strong laws to safeguard stereotyping or discrimination.

This study explored the unexplained gender gap of newspaper leadership. The hypothetical question was not why women do not go into editorships, but what is the impetus and perceived barriers for those rare women who do attain the position.

\section{Literature Review}

Empirical evidence throughout the Western world indicates that women have a diminutive role in daily newspaper decision-making - producing only about a third of the news. In the print news, the majority of bylines (which indicate who researched and wrote the story) were male 63 percent to female 37 percent, in a survey of 114 countries (GMMP 2015).

When it comes to the top decision-making position in the newsroom, the editor, it is more difficult to gain concrete figures. There are no regularly conducted global surveys on newspaper leadership by gender, and those that have been conducted rely on media companies to volunteer to participate. In Britain, only 18 percent of the main daily newspapers are edited by women, and only 25 percent of their front page stories are written by women journalists (Mills et al., 2017), leading to a call from the deputy opposition leader for the news media to ensure half its political reporters are women (Ruddick, 19 Sept. 2017). A global 
survey across 59 countries showed men held 73 percent of top management spots (such as publishers and CEOs), 61 percent of senior management jobs, and 71 percent of middle management roles (Byerly, 2011).

The persistent gender gap in newsroom leadership has been called a crisis by the USA Women's Media Center (2013), and prompted nationwide editorial forums on how to bring more women up the ranks, as well as research funded by the American Press Institute and the Pew Centre for Journalism Excellence among others. There is at least lip service by the newspaper industry that it wants more women editors, but this still has not happened. The 2017 Women Media Center report concluded men still dominate all areas of the media "with change coming only incrementally... Women are not equal partners in telling the story, nor are they equal partners in sourcing and interpreting what and who is important in the story" (WMC, pg 3).

The unexplained lack of women in the top job of newspapers is the same in New Zealand as other countries, with a consistent drop off of women going up the career ladder. This is described as a "funnel model" (Strong, 2011) whereby many women enter the profession, but a majority drop out the first two years, and many more drop out in subsequent years. Women make up 76 percent of NZ journalism students (Barnes, 2015) but only 46 percent of print articles are written by women (GMMP, 2015) and only an average of 14 percent of daily newspaper editors are women (Strong, 2011).

Women working in the news media have been under the spotlight for decades by newsroom culture theorists who contend that if more women at the top would result in a different, and better, selection and treatment of news (WMC 2017, GMMP 2015). Although various studies have conflicting conclusions regarding whether or not a female editor makes any different news judgements to male editors, especially as she has had to succeed in the existing environment (Beam \& Di Cicco, 2010; Everbach, 2006; Melin-Higgins, 2008), the industry lacks enough volume of gender balanced editors to explore this point.

There have been many studies, however, that indicate women journalists use a wider selection of sources than comparable male journalists (WMC 2017, GMMP, 2015) and that topics such as rape and reproduction are covered more when women make the news judgement decision (ibid.). The reputable media research institute NiemanLab, found journalists tend to use more sources of their own gender. The report points out that since a vast majority of news items are written by men (ratio of almost 2:1) this means the sources in stories are mainly men, even on such women-specific topics of as reproduction, campus rape, and sexual assaults (Wang, 2017).

The newspaper journalism environment has been described as masculine, autocratic and aggressive by a variety of news culture scholars over the past 40 years. Although the term 'masculine' is inappropriate, as many journalists of 
both genders find the environment intolerable (Strong, 2012) this is the term used in previous literature. Bourdieu (2001) criticised the journalism culture as heavily masculine to the point of excluding feminine styles, while Creedon (1993), Byerly (2004) and Lavie (2004) agree that women do not progress into management because of an invisible barrier that only allows entry to their male colleagues. Bourdieu blamed the barrier on unwritten rules for promotion in the newsroom that are intangibly revealed to male journalists, but not to women. He gave the example that men are assigned hard news stories which leads to promotion, while women are assigned soft news stories that sidelines them from the leadership career path (2001).

Other than the embedded newsroom culture, the reason for women not gaining editor positions is unclear. Melin-Higgins' study in Europe (2008) indicated the path to senior management in the media either remains blocked, or demands compromises that women journalists are choosing not to make, and instead remain in lower positions or specialise in areas not in the executive career ladder. In Australia, North (2012) posits that women's reluctance to pursue editor roles may be linked to a sex-based wage gap: the gender pay gap is smallest when journalists first enter the Australian industry, and progressively increases, to reach a 21 percent disparity for women aged 45-54 (ibid). In New Zealand a similar pay disparity has been identified, where female journalists are paid 26 percent less than their male colleagues (Hollings et. Al., 2016).

One theory to explain women's reluctance to enter, or remain, in leadership roles is the isolation from being the sole woman, described as 'collegial wilderness' (Strong, 2011), whereby a manager is unable to discuss office issues or concerns with a trusted same-gender peer. A female editor is isolated from the others in management who are male; at the same time she no longer remains in the journalists' collegial networks, as they are her employees and no longer her peers. 'The female editors are placed in a harsh management environment of tough work conditions and unchartered decision-making responsibility, but are not armed with the support system, particularly from their peers, to conquer it easily' (p. 288).

Research in other disciplines confirms that professional collegiality is an important part of workplace success and that it leads to better decision-making (Feiger \& Schmitt, 1979; Reinken, 1998). Even the classic Maslow Theory of Productivity (Maslow, 1943) identified that corporate leaders were more productive when they had a feeling of belonging. Strong (2011) suggests that the female editors lacked a feeling of Maslow's 'belonging', and being in the collegial wilderness took away one possible management tool in the economic and technical crisis currently facing the newspaper editors.

The economic crisis facing newspapers is due to its traditional readers and advertisers shifting to online platforms, rather than the hard copy publication, 
leading to cuts in resources and increased stress on management (Reinardy, 2011). In response many news organisations are putting resources into online news websites, which create modern and different jobs - and different management structures (Sylvie, 2011). Scholars have warned that as the newspaper industry faces the long-term erosion of its traditional business model, issues of gender parity may drop down its list of priorities (WMC, 2013; Barnes, 2015).

These industry changes are evident in New Zealand and all daily newspapers have an online platform, which has led to more cooperation among news producers of different newspapers within the same ownership. Hence, the internewspaper competition is less pronounced as all newspapers in the same company provide news for the company-wide online platform, which is NZME's herald. co.nz and Fairfax Media's stuff.co.nz (Myllylahti, 2017).

These technical and structural changes within the daily newspaper industry makes it an opportune time to further examine the gender balance of leadership in New Zealand and particularly the enticers and barriers for women leaders. This study explores the current stage of women daily newspaper editors in New Zealand and asks the questions: How is the proportion of female editors trending? What are the enticers and barriers for narrowing the gap? Does the current state support or refute the collegial wilderness theory?

\section{Research method}

This study interviewed all women who have held the position of editor of a daily newspaper in New Zealand. The newspapers were published at least six days a week, in a hard copy edition, whether or not they also had an online edition. All 22 daily newspapers were researched historically to determine current and previous editors and their gender. At the beginning of this project there were 22 daily newspapers in New Zealand, and this has decreased to 19 with the closure of three publications due to economic issues. Only one of the newspapers that closed was edited by a woman editor at the time.

Individual interviews were conducted by the author with all 15 women who have held the position of editor of a daily newspaper since 1992, believed to be a census of women who have ever held this position in the country. The questions were open-ended to allow the participants to determine their own priorities and narrative. The interviews were held face-to-face in most instances, usually with a pre-interview and also post-interview session. This study has been vetted through Massey University Research Ethics unit. The participants were provided with the question outline, and all interviews were recorded, and the recordings were either destroyed afterwards or held in a secure digital file. The interviews began in 2008 and continued until late 2017. All female daily newspaper editors agreed to participate in this study. One participant took several years to track down, as she had left the country and her previous employers could not provide 
forwarding contact details. This participant plus three others were interviewed on phone or Skype instead of in person.

\section{Results}

Most women who have lead a daily newspaper also have the distinction of being the first woman editor for that particular newspaper, and most newspapers had been in publication for about 150 years before appointing a woman to lead it. Only four newspapers have had two women editors in their history (Manawatu Standard, Marlborough Express, Waikato Times, Dominion Post), while six of the country's remaining 19 daily newspapers (32 percent) have never had a woman editor (New Zealand Herald, Otago Daily Times, Taranaki Daily News, Gisborne Herald, Greymouth Star, Ashburton Guardian). One editor interviewed pointed out that the newspapers were facing too many challenges for survival, and therefore gender equality in leadership was not on their radar.

Over the past 25 years women on average made up only 14 percent of the editors. Although there was a sharp increase in 2015, when Fairfax appointed women to four of its daily newspapers. This increase still represented only 29 percent of daily editors, and in mid-2017 one woman-led newspaper closed, and in early 2018 another editor left the job, bringing the tally to 21 percent editors women compared to 79 percent men.

The attitudinal findings from the women who had been appointed prior to 2012 are listed below as the First Ten editors. These ten were appointed at a time when there was keen competition among newspapers, and before the proliferation of their digital multi-platform production, and the surge of social media. The second group, called the New Crop entered the job after 2012 (most in 2015) and work in an atmosphere where digital news leads, thereby less competition

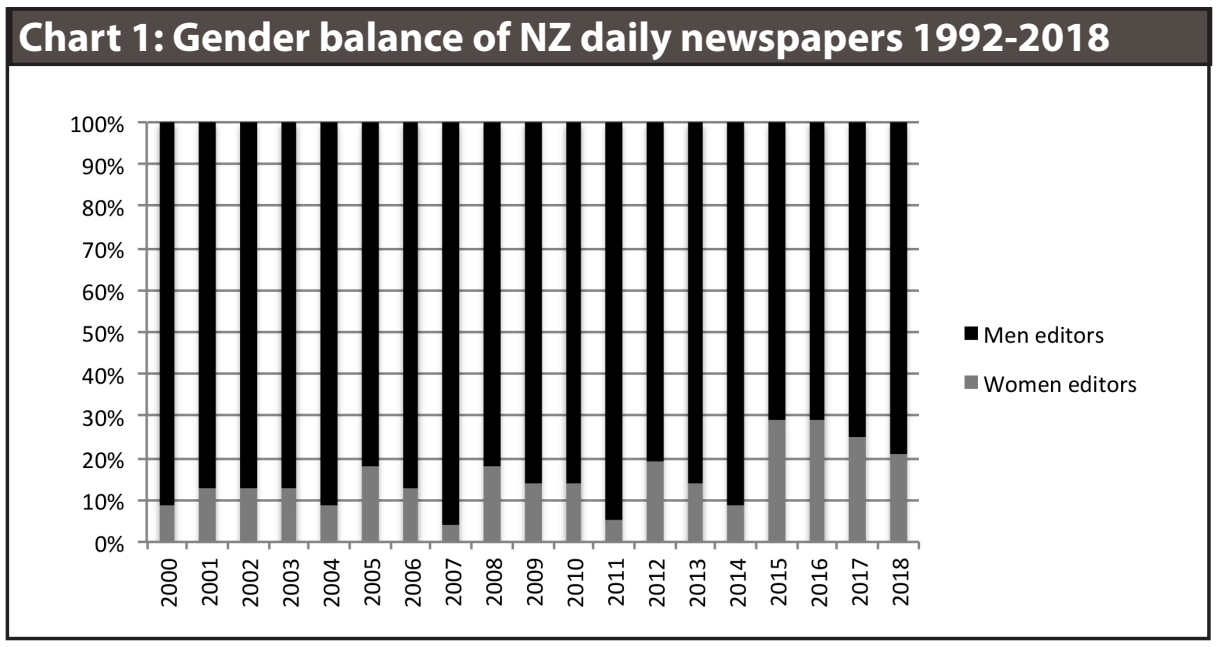


among newspapers within the same company, and more collaboration for the company's online website.

There were many similarities among all 15 of the research participants, such as that most had not thought of applying for the editor's job until one particular person urged them to do so, which this research calls 'shoulder tapped'. They still had to apply for the position, but the enticement was that an executive told them they were ready for the job. All except two participants said they would not have applied for an editor job without this level of encouragement. For the First Ten this encouragement came from two particular men who held executive positions at the two large, competing media companies. Most of the New Crop said one influential female executive in Fairfax Media had a deciding influence in their considering an editorship career path. All women editors appointed since 2012 were by the same media company, Fairfax, which owned eight (42 percent) of the country's 19 daily newspapers.

\begin{tabular}{|l|c|c|c|c|}
\hline \multicolumn{5}{|c|}{ Chart 2: Journalism experience prior to editorship (N=15) } \\
\hline Ave=17.5 & $\mathbf{2 0 + \text { years }}$ & $\mathbf{1 5 - 2 0}$ years & $\begin{array}{c}\mathbf{1 4} \text { years or } \\
\text { less }\end{array}$ & Total \\
\hline Total & 5 & 8 & 2 & 15 \\
\hline
\end{tabular}

Another similarity among all editors was is that before applying for an editor position most (67 percent) had been a journalist for more than 18 years, and all except two ( 87 percent) had been a journalist for more than 15 years. Most were experienced in both reporting and production, and those appointed in the recent decade took a lead in digital production. The majority of them had no formal preparation for the leadership position, with 74 percent reported receiving no management training before being given the job, and this was consistent throughout the 25 years. As one said, 'they gave me a staff, a million-dollar budget and said go-for-it'.

\section{Results: The First Ten appointed prior to 2012}

The duration of their editor career is fairly short, with the average length being less than 3 years. In almost every case, the women continued working in newspapers and as journalists, after stepping down — sometimes at the same newspaper they had previously managed. Only two women were editors for 10 years, one stepped down for health reasons, and the other for a corporation promotion. One short-term editor said this study's research question should not be how to get more female editors, but how to get them to stay longer than three years.

These women left for a combination of reasons, and this research is limited to what they revealed during their interviews, acknowledging that the situation may have been more complex than described. Five said they stepped down for 


\section{Chart 3: Length of time as editor (pre-2012, $\mathrm{N}=10$ )}

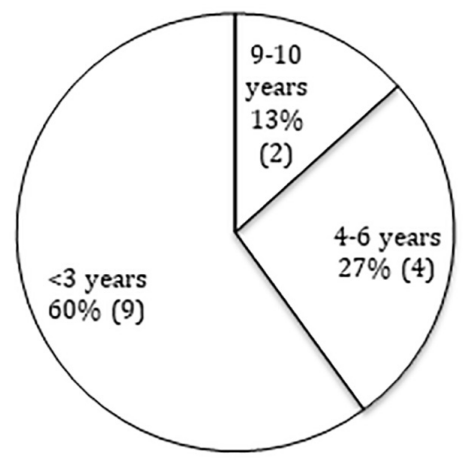

reasons of ill health or family reasons; three said it was for 'frustration' at the job, one for a promotion within the corporation, and the remaining two left without any information on the reason.

In addition, these participants tended to end their editor careers relatively abruptly. One editor said she quit hastily within days of making the decision, three others quit suddenly giving the minimum contractual notice, some with little explanation. A fourth quit unexpectedly when her contract finished, despite the media company's expectations she would continue.

Most female editors commented on the lack of management help available, such as not being given a personal assistant. They pointed out that much higher executive salaries and benefits would be provided in other industries where the person in the top position managed a staff of dozens plus a budget of more than a million dollars. The female editors, however, made it clear that the lure of the position was not salary, and that they could find an easier job with higher pay if that was their career agenda.

\section{Overall assessment of the editor experience}

The female editors said they enjoyed the challenges and satisfaction of holding the position. Even those who held the position for a relatively short time spoke enthusiastically about 'the buzz' of being an editor. A woman who quit from exhaustion used the word 'loved' seven times when talking about the positives of being an editor. Here are comments from the nine women who left the job:

- 'The best job I ever had! You would have heard of the long hours and pressure, but the pleasures outweigh the pressures. The joy of being at the wheel.'

- 'What made me stick to it is that I enjoyed it. I really loved the (newspaper) and it meant a great deal to me.' 
- 'The satisfaction of when you look at the newspaper and you think "yes, I'm responsible for pulling that all together", and know that sense of achievement.'

- 'Steering the whole product is pretty cool.'

- 'It is a privilege to be the editor. I considered it an honour to even be considered...I enjoyed being a leader. I enjoyed working with people... I loved it, really loved it.'

- 'I enjoyed leading the reporters' team, as well as the community.'

- 'Knowing that this product that comes out every day is something you had a huge part in, and you are responsible for. It is satisfying, hugely satisfying.'

- 'It was very rewarding. It was very fulfilling. We did some fantastic campaigns, fought some good battles, which is what journalism is all about in the end-to make the world a better place. It was wonderful to do this.'

- 'I just love working with a team, and with the newsroom that is firing, the trouble shooting, the pulling things together in a hurry with a team of skilled people, and the laughs you have with a team of people. I'd miss it.' On the surface the superlative quotes above seem incongruous with the fact that most of the editors worked in a newsroom an average 18 years before taking over the leadership position of editor-but then stepped down from it within 3 years.

\section{Positive aspects of the position}

The most often-cited positive factor of being an editor was the creative aspect of coordinating many elements to produce a quality publication every day. Some said part of the creative element was the combination of moulding the staff, the stories, and the page design each day to complete the task. 'You go in the morning to face big reels of empty newsprint, and before lunchtime you have filled those with what you hope is the best product, with the best news of the day, and you can see that,' said one editor.

The second positive factor of being an editor was working on behalf of the community. Most saw the editor as a leader in the community, but in a special position also as guardian of public information, because the newspaper was often the main published platform within a community. They described their self-expectations to attend community meetings, accept speaking requests and network with a wide variety of community leaders. Several women outlined specific social justice campaigns they led to change or encourage a community project. As one said, 'I loved campaign journalism, bringing some change that wouldn't have happened otherwise.'

The third major positive aspect of being an editor, reported by participants, was working with the newsroom team. They spoke enthusiastically about nur- 
turing new journalists, and being able to fit the right person into the right position. They indicated they had autonomy to choose staff and create a team. One editor consistently referred to 'we' in describing the jobs and responsibilities she did. Another gave an example of working with an inherited non-productive staff member to turn him into a 'star' staff member. A third described the joy of hiring young reporters: 'I love the excitement of when you offer someone a job and they scream excitedly down the phone, because they finally got that break. I love that part.' However, two editors said staffing was one of the frustrations that led them to quit the job, noting they had inherited an established staff and lacked the ability to hire in new people.

\section{Negative aspects of the position}

A major negative mentioned in an open-ended question was collegial loneliness or isolation, often exacerbated because of the lack of same-gender peers. Collegial isolation was given by 90 percent of the First Ten experienced editors as a major problem being an editor. (One participant was not asked, as she had only taken up the job at the time of the interview.) One part of this isolation was that the participants were required to shift environments and in most cases shift geographic locations in order to take up a sole management position. Further, the management position was the traditional newspaper sole responsibility, in stark contrast to their previous journalism position in a highly gregarious newsroom environment where reporters often socialised both at work and out of work with the same people for years. The participants described having spent many years in a 'party' or 'pub-going' culture, often exclusively with other journalists, a uniting bond necessitated by the odd working hours not shared by other occupations. As most of these women had been newsroom journalists for more than 18 years prior to being editors, the relationship forged with newsroom journalists was very close. But once they became an editor they had to distance themselves.

However, a more pressing form of loneliness they discussed was the lack of collegiality with other editors. They gave examples of wanting to discuss editorial issues with peers, but not being able to, mainly because there was a lack of reception from other editors, but also because the mechanisms for discussion did not exist. Seven participants described a gender-specific dichotomy in career paths. They reported that men often knew earlier in their career that they would become editors and therefore bonded with similar upwardly mobile men well before they became editors, and became editors much earlier in their careers. Women, on the other hand, did not see themselves as potential editors until later in their career, so did not necessarily bond with upwardly mobile journalists in the early stages. Two of the participants described this dichotomy as leading to new female editors having to "prove themselves; to the other editors, whereas 
male editors did not have that need. One editor described an incident when she pushed ahead with an email discussion forum with other editors, using the topic of a controversial decision on a story placement. However, the forum was rebuffed by the other male editors who did not see the need for discussion, and even sent what she called 'very patronising' comments back to her. So she ceased further attempts at professional collegial discussions. Another participant said, 'I could make decisions, but at times wanted to discuss it with other editors. This wasn't possible. They didn't want to question their own decisions.' And yet another participant said she was 'belittled' if she wanted to debrief on treatment of a particular news item.

The lack of collegiality is not confined to female editors, as the participants described an industry-wide difficulty in finding opportunity to liaise with their peers in other cities. Several said it was only their company annual editors' conference when they could discuss issues with their peers.

The other major negative part of the job was the long hours, with six participants reporting that they regularly spent 11 hours a day in the office. This caused problems keeping commitments with family members, and losing contact with long-time friends as most of these editors had to shift cities to take up the editorship. Several participants discussed in detail how the economic problems within the industry have led to a reduction in staff numbers, with even more work for those remaining. The participants pointed out that an editor is the sole person with the responsibility to ensure the job is done before the newspaper is due for publication each day, despite staff cuts made by their corporate media company. 'I couldn't delegate because everyone else had a heavy work load,' said one. Another said: 'People get burned out quickly because there is a thin veneer of people at the top doing the job.'

\section{Results: The New Crop editors appointed after 2012}

Most of these five editors have been in the position too short a time to compile reflective attitudes to the job, as described by the earlier editors above. They all mentioned the enthusiasm to working on behalf of the community, but also mentioned the frustration with budget cuts. They all considered it a positive part of the job to work with their staff, particularly developing young journalists.

Unlike the earlier editors, these new age editors have to deal with social media trolls. They commented that this is time consuming and energy sapping. In one case she almost had to get legal restraints on one person who consistently made threats on social media. Most said trolls who used social media to toxically criticise the editor or the newspaper's work, were 'annoying' but they were able to put it in perspective after talking to other editors.

This talking to other editors is the major difference between the New Crop of editors and those women who were editors in earlier years. They newer ones 


\section{Chart 4: Editor's family responsibilities}

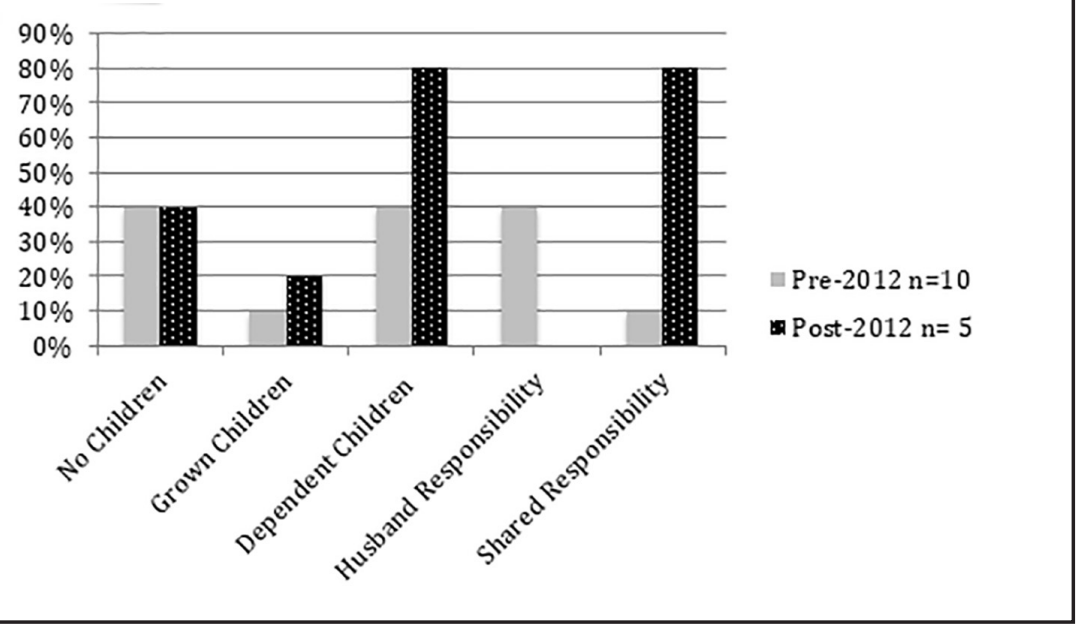

have professional collegiality, although they used different terminology. Every current editor said the regular discussions with other women editors helped make the job easier. Some said after they discussed the latest social media trolls they could laugh it off. Others said it was strengthening to see other editors were dealing with the same staff issues or news-gathering issues as themselves. Several said that right at the beginning they found it more inclusive when they went into the job interview and was not facing a panel of all older men.

Another change in environment for the New Crop was that digital technology meant they could work away from the office, even at home or in the car if they had child care responsibilities. They said they worked long hours, but could be free of sitting at a desk or being physically present in the newsroom. Many of their reporters were working from various venues, so it was common to use digital, and not physical, communication.

These digital advantages may explain why none of the recent appointees had to rely on having a partner who gives up his job to allow her to pursue the high pressure editorship. In previous years 40 percent of editors said their partners had to alter their careers in order to be what they called, 'house-husbands' when they accepted the editorship. As shown in Chart 4, twice as many of the New Crop editors have dependent children, and eight times more share child rearing with their partner, compared to editors in earlier years. Although the actual numbers are too small for the statistics to be significant, it does indicate these women with dependent children are now becoming editors whereas it was not the case in earlier years.

\section{Conclusion}

Despite the enthusiasm for journalism leadership, and the vast experience they 
bring to the role, women editors tended to quit the job after only three years. Their love of newspaper journalism remains high, as indicated by their comments, but also by the fact they remain working in the industry after they step down as editor. This indicates that the position of editor is not desirable enough to outweigh the negative aspects, and that it is the editor position that is unattractive, not the newspaper industry or journalism career. As outlined in the literature review, many groups see low retention rate of female newspaper editors is a blow to leadership diversity and a deterrent to gender-balanced news reporting.

Women became editor only after they had more than 18 years journalism experience behind them, but they were still surprised when an executive urged them to apply for an editorship - even those who had more than 20 years prior experience reported surprise at being shoulder tapped for the editor position. Most editors would not have applied without this encouragement; and prior to becoming editor most did not receive management or financial training, or any other form of preparation. These findings support theories by Bourdieu and other newsroom culture scholars that the industry does not groom women for management; the unwritten guidelines and encouragement for management promotion are not revealed to women the same way they are for men.

Once in the editor's position, the women in this study said the positive aspects were working with staff, the community, and the creative aspect to news production; but they identified the negative aspects as the long hours, stressful decisions, and professional isolation (being in the collegial wilderness).

A significant difference in the editors appointed more recently, since 2012, is that none mentioned isolation or lack of professional collegiality, as did the editors who served earlier. Having a feeling of professional collegiality seems to be from the fact there is a volume of other female editors available to discuss management issues. On a broader scene, the digital newsroom allowed editors to more easily combine work and family/friends while still working long hours. As described in the literature review, employers who feel they have professional collegiality are more successful and more satisfied with their work environment. In the case of the current editors, they all work for the same media company and could ethically discuss management issues with each other. The sheer increase in women editors has created a more gender balanced executive tier that eliminated their being the sole woman leader, which supports the collegial wilderness theory.

One milestone is that in 2018 one editor completed ten years of editorship, a NZ record for female newspaper leadership. She resigned to take up a promotion in the media corporation that owned her newspaper.

Although this increase is considered good news when viewed over the decades, it is disappointing and perplexing that in the 21 st century an industry that faces an army of qualified women completing journalism qualifications, can only celebrate that the gender imbalance is whittled down to a one-fifth share 
of the top editor position. Despite the strides the country has taken in many other gender equality arenas, this study indicates that over recent years only 14 percent of daily newspaper editors have been women. The ratio has grown to 21 percent since 2015, but further research is needed to determine if this is a trend or an aberration.

A disturbing finding of this study is that female journalists wait until someone in authority urges them to think about being an editor; and that they seem to escape notice until they have been a journalist for an average of 18 years, a long time. This indicates that female journalists are not groomed or encouraged towards editorships in the earlier years of their career, which is in line with Bourdieu's theory that women are denied the unwritten rules for newsroom promotion. It is partly the women's fault in avoiding career planning, but it is also the fault of the industry in not providing a transparent gender-free career path. There were four specific executives throughout the decades who have taken the step of tapping the shoulder of an experienced female journalist and alerted her to an editor job that was within her grasp.

A promising finding of this study is that since 2012 there seem to be women executives as models, and who urge female journalists to consider an editor job. One current editor said clearly that she probably would not have pursued the job if she thought she would be facing a panel of only men in the job interview; but now there are women at the top table and there no longer exists the deterrent of a male-only selection panel. The limitation to this research is that it is evolving, and many of the newer editors have not been in the position long enough to determine trends.

In conclusion, the number of women leading New Zealand's daily newspapers is still low but seems to be increasing. The leadership may become more gender balanced now that there are more women at the top to be role models and part of professional collegiality; thereby eliminating the collegial wilderness previous female editors experienced. This professional collegiality may also create an environment whereby women decide to remain in editorships longer than they did in the past.

\section{References}

ASNE (2017). 2016 ASNE diversity survey. Columbia, MO: American Society of News Editors. Retrieved from asne.org/diversity-survey-2017

Amory, E. (2015, February 15). Why print newspapers remain the dominant media power in Britain. The Guardian, UK: Guardian News and Media Ltd. Retrieved from www.theguardian.com/media/greenslade/2015/feb/16/why-print-newspapers-remainthe-dominant-media-power-in-britain

Aucoin, D. (2017, June 30). Print reporters - and the stories they break—reach a broad audience on cable news. The Boston Globe. Retrieved from www.bostonglobe.com/ 
arts/2017/06/29/print-reporters-and-stories-they-break-reach-broad-audience-cablenews/qtN08AAUkTRKxyrkRE1YTN/story.html

Barnes, L. (2015). An inexplicable gap: Journalism and gender in New Zealand. Journalism, 18(6), 736-753.

Beam, A., \& Di Cicco, D. (2010). When women run the newsroom: Management change, gender, and the news. Journalism \& Mass Communication Quarterly, 87(2), 393-411.

Bourdieu, P. (2005). The political field, the social science field, and the journalistic field. In R. Benson, \& E. Neveu (Eds.), Bourdieu and the journalistic field, (pp. 29-47). Cambridge: Polity Press. 'í

Bourdieu, P. (2001). Masculine domination. Stanford: Stanford University Press.

Byerly, C., \& Ross, K. (2006). Women and media: A critical introduction. London: Blackwell.

Byerly, C. (2011). Global report on the status of women in the news media. Washington DC: International Women's Media Foundation.

Creedon, P. (1993). Women in mass communication. Beverley Hills: Sage.

Creedon, P. (1989). Women in mass communication: Challenging Gender Values. Newbury Park: Sage.

Creedon, P., \& Cramer, J. (2007). Women in mass communication [Third edition]. London: Sage.

de Bruin, M., \& Ross, K. (2004). Gender and newsroom cultures: Identities at work. Cresskill: Hampton Press, Inc.

Everbach, T. (2006). The culture of a women-led newspaper: An ethnographic study of the Sarasota Herald-Tribune. Journalism \& Mass Communication Quarterly, 83(3), 477-493.

Feiger, S., \& Schmitt, M. (1979). Collegiality in interdisciplinary health teams: Its measurement and its effects. Social Science \& Medicine, 13, 217-229.

Fountaine, S. (2015). New Zealand global media monitoring project 2015, national report. Who makes the news. WACC: Toronto. cdn.agilitycms.com/who-makes-the-news

GMMP (2015). Global media monitoring project 2015. Who makes the news. WACC: Toronto. Retrieved from whomakesthenews.org/gmmp-2015

Gray, A. (1984). Women in the media. Auckland and Wellington: Media Women

Hollings, J., Hanusch, F., Balasubramanian, R., \& Lealand, G. (2016). Causes for concern: The state of New Zealand journalism in 2015. Pacific Journalism Review, 22(2), 122-138

Maslow, A. (1943). A theory of human motivation. Psychology Review, 50, 370-396.

Melin-Higgins, M. (2008). Gendered journalism culture: strategies and tactics in the fields of journalism in Britain and Sweden. Gothenburg: University of Gothenburg.

Mills, E., Hind, K., \& Quinn, A. (2017). The tycoon and the escort: the business of portraying women in newspapers. Women in journalism. UK. Retrieved from womeninjournalism.co.uk

Myllylahti, M. (2017). JMAD New Zealand media ownership report. Auckland, NZ: Centre for Journalism, Media and Democracy, Auckland University of Technology.

North, L. (2012). 'Blokey' newsrooms still a battleground for female journalists. Australian Journalism Review, 34(2) 57-70.

Poindexter, P. (2008). Finding women in the newsroom and in the news. In P. Poindexter, S. Meraz, \& A. Weise (Eds.), Women, Men and News (pp. 65-83). New York: Routledge.

Reinardy, S. (2011). Newspaper journalism in crisis: Burnout on the rise, eroding young journalists' career commitment. Journalism, 12(1) 33-50.

Reinken, B. (1998). System of collegiality: A theory of professional collegial relation- 
ships in secondary schools. American Educational Research Association. San Diego, CA: AERA.

Ross, K. (2004). Sex and work: Gender politics and newsroom culture. In M. de Bruin, \& K. Ross (Eds.), Gender and newsroom cultures: Identities at work, (pp. 145-162). New Jersey: Hampton Press, Inc.

Ruddick, G. (2017, September 19). Tom Watson urges newspapers to boost number of female political journalists. The Guardian: UK. Guardian News and Media Ltd.

StatsNZ (2017). 100,000 record population growth. Population, Statistics New Zealand, New Zealand Government. Retrieved from www.stats.govt.nz

Strong, C. (2011). Female journalists in New Zealand daily newspapers: From early career to gender gap in editorship. Unpublished doctoral thesis. Wellington, NZ: Massey University.

Strong, C. (2012). Gender disparity in daily newspaper journalism: Glass bubble replaces glass ceiling. Presentation at the 'Fast accurate net in journalism education' conference, 29-30 November, Wellington, NZ: Journalism Education Association of New Zealand (JEANZ). Retrieved from www.jeanz.org.nz

Sylvie, G. (2012) Newsroom decision-making under new management. Portugal: MediaXXI.

Tai, Z., \& Chang, T. (2002). The global news and the picture in their heads. Gazette: The International Journal for Communication Studies, 64(3), 251-265.

Wang, S, (2017, March 22). The gender gap persists at many top news outlets in the US, and it's reflected in how stories are reported. NiemanLab. Retrieved from www. niemanlab.org

Wendland, M. (2002, December 18). Convergence: Repurposing journalism. The Poynter Institute. Retrieved from www.poynter.org/news/convergence-repurposing-journalism

WMC (2013). The status of women in the US media 2013. New York, NY: Women's Media Centre. Retrieved from wmc.3cdn.net/51113ed5df3e0d0b79_zzzm6go0b.pdf WMC (2017). The status of women in the US media 2017. New York, NY: Women's Media Centre. Retrieved from www.womensmediacenter.com/reports/the-status-ofwomen-in-u.s.-media-2017

DrCatherine Strong is a senior lecturer in the School of Communication, Journalism and Marketing at Massey University, Wellington. She has worked as a senior journalist at RNZ National, Television New Zealand, Akron Beacon Journal and Solomon Islands Broadcasting. Her research focusses on current journalism practices and she has introduced drone journalism and podcast production to core courses.

C.R.Strong@massey.ac.nz 